\title{
RENAL VENOUS PRESSURE IN CHRONIC CONGESTIVE HEART FAILURE ${ }^{1}$
}

\author{
BY MORTON H. MAXWELL, ERNEST S. BREED, AND IRVING L. SCHWARTZ 2 \\ (From the Department of Physiology, New York University College of Medicine, and the \\ Third [New York University] Medical and Surgical Divisions of Bellevue \\ Hospital, New York City)
}

(Received for publication September 15, 1949)

In the recent literature there has been a revived interest in the role of the kidney in congestive heart failure, particularly with reference to the mechanism of sodium retention and edema formation (112). In view of the contention by Blake and his associates (13) that a rise in renal venous pressure in the dog may prevent excretion of sodium without altering renal blood flow or filtration rate as measured by clearance methods, and its possible implications in man, it was felt that actual measurement of renal venous pressure in subjects with congestive heart failure was indicated. A review of the literature revealed that there were no previous measurements of renal venous pressure in normal human subjects other than the six figures cited by Bradley and Bradley (14) who, for their purposes were more concerned with comparative pressures before and during abdominal compression than with a precise set of normal values. The purpose of this communication is 1) to establish a standard technique and set of normal values for renal venous pressure measurements in man, and 2) to report on renal venous pressure in patients with congestive heart failure, discussing the significance and the hemodynamic mechanisms involved.

\section{MATERIALS AND METHODS}

The control subjects were all patients in Bellevue Hospital with no evidence of cardiovascular or renal disease. Most of them had benign lesions, such as leg ulcers, or were convalescent and about to be discharged from the hospital. The subjects with congestive heart failure had such evidence of right-sided failure as ankle edema, distended liver, pulsating neck veins and increased peripheral venous pressure as measured on the ward; the degree of left-sided failure was variable.

\footnotetext{
1 Aided by a grant from the Commonwealth Fund.

2 National Institutes of Health Postdoctorate Research Fellow.
}

Some subjects were under treatment with digitalis and salt-free diets at the time of study.

Pressure measurements were incorporated as part of general renal function studies, which usually included renal clearances, extraction ratios and oxygen consumption by the kidneys. The renal venous pressure was measured at the start and termination of the other studies; the pressures from the inferior vena cava, right atrium and arm vein, when recorded, were obtained during withdrawal of the catheter.

The general procedure was as follows: a No. 9 or No. 10 radiopaque ureteral catheter was passed under fluoroscopic observation through an antecubital vein into the right renal vein as described by Warren, Brannon, and Merrill (15). The subject was supine with the head elevated on a pillow, and a slow flow of heparinized saline from a reservoir was maintained between pressure determinations to prevent clotting within the catheter. Direct readings were made on the saline manometer, with repeated elevation of the pressure above equilibrium. When there was any question as to equilibrium, or if consecutive determinations were not within $5 \mathrm{~mm}$. of each other, slight positive pressure was applied into the top of the manometer, thus permitting the saline column to rise, rather than fall, to equilibrium. The site of the cutdown in the antecubital fossa was well novocainized, and every effort was made during the entire procedure to keep the patient psychically and physically comfortable.

An arbitrary zero point of $10 \mathrm{~cm}$. above the table top was originally assumed for renal vein and inferior vena caval pressures. This was later checked by lateral $\mathrm{X}$ rays on seven subjects, which showed the tip of the catheter in the renal vein to vary from 5.3 to $13.0 \mathrm{~cm}$. above the table top, with an average of 9.4 , most of the figures being closely grouped around the average. The original reference point, $10 \mathrm{~cm}$., was therefore used in subsequent measurements. The reference point for atrial and peripheral pressures was taken at $6.6 \mathrm{~cm}$. below the angle of Louis, in accordance with the recommendations of Cournand and his colleagues (16).

When the catheter tip was in the renal vein or inferior vena cava, there were pressure fluctuations with each respiration of about 5 to $15 \mathrm{~mm}$. saline; when in the right atrium there were respiratory, and perhaps cardiac, fluctuations of similar magnitude. All readings represent the approximate mid-point of these movements.

That the catheter was actually in the renal vein was always verified by the $\mathrm{PAH}$ and $\mathrm{O}_{2}$ extraction ratios. 
TABLE $\cdot$ I

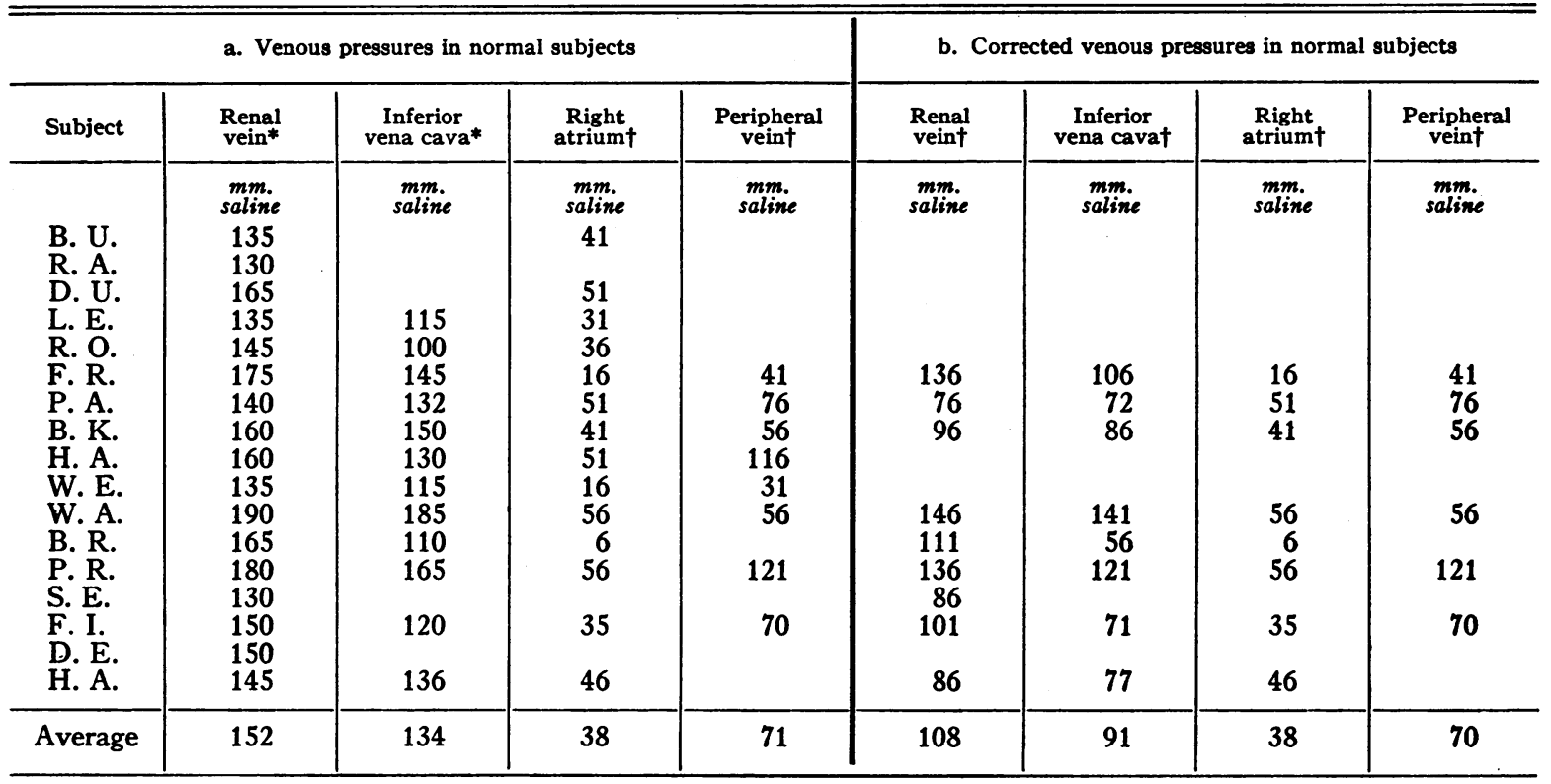

* Zero point $=10 \mathrm{~cm}$. above table top.

$\dagger$ Zero point $=6.6 \mathrm{~cm}$. below angle of Louis.

\section{RESULTS}

Renal venous pressures were measured in 17 normal subjects. In addition, pressures were taken from the inferior vena cava in 12 , the right atrium in 14 and the axillary or brachial vein in eight of these subjects (Table $I, a)$. The renal venous pressures ranged from 130 to $190 \mathrm{~mm}$. of saline, averaging 152 . Those from the subdiaphragmatic inferior vena cava ranged from 100 to 185 , averaging $134 \mathrm{~mm}$. The right atrial pressures averaged $38 \mathrm{~mm}$., varying from 6 to 56 . The peripheral venous pressures averaged $71 \mathrm{~mm}$., with a range of 31 to 121 .

TABLE II

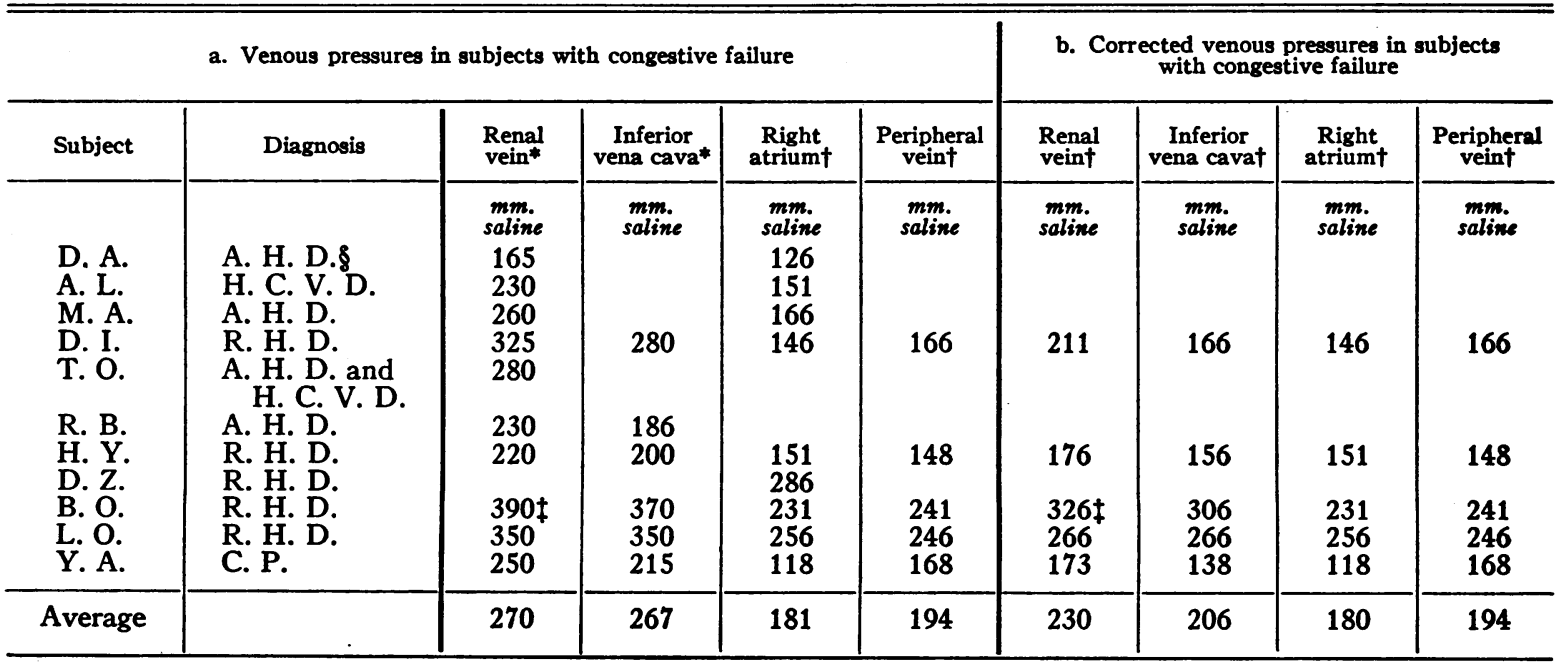

* Zero point $=10 \mathrm{~cm}$. above table top.

$\dagger$ Zero point $=6.6 \mathrm{~cm}$. below angle of Louis.

$\ddagger$ Value assumed to be $20 \mathrm{~mm}$. higher than vena caval pressure.

A. H. D. = arteriosclerotic heart disease; H. C. V. D. = hypertensive cardiovascular disease; R. H. D. = rheumatic heart disease; C. P. = cor pulmonale. 
In the subjects with congestive heart failure, ten renal venous pressures (Table II, a) ranged from 165 to 390 , averaging $270 \mathrm{~mm}$. ; ${ }^{8}$ six inferior vena caval pressures ranged from 186 to $370 \mathrm{~mm}$., averaging 267 ; nine right atrial pressures averaged $181 \mathrm{~mm}$., with a range of 126 to 286 ; and five peripheral venous pressures varied from 148 to $246 \mathrm{~mm}$., with an average of 194.

It will be seen that the pressure in all parts of the venous system in subjects with congestive failure is considerably higher than in the control subjects. Individual pressures in the cardiac subjects roughly paralleled the clinical condition of the patient, usually being higher in cases of more severe decompensation.

The results of other renal function tests performed on patients with congestive failure were in accord with those found by other investigators $(3$, $7,8)$ : renal plasma flow was reduced about $2 / 3$, filtration rate reduced about $1 / 3$, the extraction ratio of PAH was normal (0.88 to 0.96$)$, the oxygen $\mathrm{A}-\mathrm{V}$ difference was increased.

Validity of measurements: Our average atrial and peripheral venous pressures of 38 and $71 \mathrm{~mm}$., respectively, in the control subjects are in close agreement with those of Cournand and his coworkers (16), their averages being 33 and $74 \mathrm{~mm}$. The average atrial pressure of $181 \mathrm{~mm}$. in the cardiac patients is lower than the figure of $203 \mathrm{~mm}$. in the four subjects with right-sided heart failure reported by Richards and his associates (17), but some of our patients were digitalized and partially compensated, which may account for the difference. The tendency of the pressure gradient from the right atrium to peripheral vein to flatten out in patients with right-sided failure, as reported by Richards and his group, is borne out in these studies.

Renal venous pressures must be interpreted with cognizance of possible artefacts inherent in the technique. The introduction of the catheter, by increasing the resistance to movement of blood within the vein, may conceivably elevate the pressure; the actual elevation in this case would depend upon how far along the renal vein the catheter

In one subject (B. O.) pressures were measured in all sites except the renal vein. $A$ renal vein pressure $20 \mathrm{~mm}$. higher than that in the inferior vena cava was assumed, since in both the normal and cardiac subjects this difference was close to $20 \mathrm{~mm}$. extended. The fact that the open lumen of the catheter was directed obliquely against the moving stream of blood might influence the recorded pressure in the renal vein and vena cava, where one would get an end pressure, whereas the pressures from the atrium and peripheral vein are lateral pressures. The possibility of spasm in the renal vein due to trauma by the catheter cannot be ignored.

In general the catheter was inserted as far into the renal vein as possible and then withdrawn about 10 to $20 \mathrm{~mm}$. before recording pressures. The anatomical variations in the apparent length and direction of the renal vein were numerous. Sometimes the catheter extended obliquely caudad from the vena cava, sometimes at about a $90 \mathrm{de}-$ gree angle, and occasionally it described a partial U-turn, the tip pointing cephalad. At times resistance halted forward motion 2 to $3 \mathrm{~cm}$. from the vena cava, and at other times the catheter extended 10 to $12 \mathrm{~cm}$. into the flank. By and large, the vena caval measurements were made with the catheter tip about $5 \mathrm{~cm}$. above the entrance of the renal vein.

In order to assess some of the above variables, repeated pressure measurements were made on two subjects at $1 \mathrm{~cm}$. intervals along the renal vein, from the point of deepest penetration to its entrance in the vena cava. Similar graded pressures were recorded along the inferior vena cava up to the diaphragm in one of these subjects, and in one other subject. This procedure revealed a gradient along the renal vein of about $15 \mathrm{~mm}$., and along the inferior vena cava of $20 \mathrm{~mm}$. In one subject in whom the catheter was forcibly inserted to its greatest possible depth, there was a drop of $40 \mathrm{~mm}$. after withdrawing $1 \mathrm{~cm}$., and in the remaining 4 $\mathrm{cm}$. of the renal vein there was an additional decline of only $10 \mathrm{~mm}$. This may represent a reactive spasm or penetration of a smaller renal venous radicle with almost complete occlusion, and could account for the unusually large difference in pressure between renal vein and inferior vena cava in several of our cases (R. O., and B. R. [Table I] ; R. B. and D. I. [Table II]).

In both the control group and the cardiac subjects with complete measurements (Tables I, b and II, b) the renal venous pressure averaged close to $20 \mathrm{~mm}$. more than that in the vena cava. The several possible sources of error in renal vein pres- 
sure measurements named above (spasm distal to the catheter tip, increase in resistance to blood flow by the catheter, end pressure) would serve to elevate but never decrease the recorded figure. Therefore, it is believed that this difference is probably artificially elevated and that the renal venous pressure is actually equal to or very close to the vena caval pressure, the resistance in the later being the determinant of both pressures. When the data of Bradley and Bradley (14), who used a reference point of $5 \mathrm{~cm}$. below the angle of Louis, are corrected for the zero point used in these studies, their renal venous pressures closely approximate our own (18).

In Table I, a and Table II, a, two different zero points have been used because the primary aim was to determine as closely as possible the actual pressures in all four sites; and the comparative pressures from each site, between the normal subjects and the cardiac subjects, are acceptable. In comparing pressure differences within the same individual, from the renal vein outward, however, we are dealing with different comparative points in a closed fluid system, and it was deemed advisable to correct the figures to a common zero point. This was possible in nine normal subjects and five subjects in failure. The common refer-

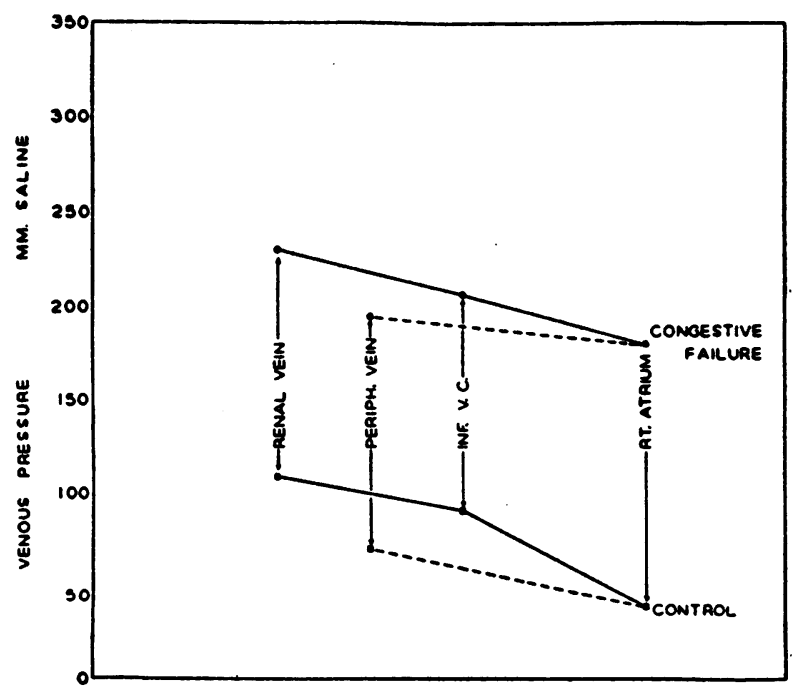

Fig. 1. Comparative Pressures from All Sites in Control Group and in Patients with Congestive Heart Failure

The reference zero point is $6.6 \mathrm{~cm}$. below the angle of Louis. The data used in the above figure are taken from Table I, $\mathrm{b}$ and Table II, $\mathrm{b}$. ence point chosen is $6.6 \mathrm{~cm}$. below the angle of Louis. This will obviously serve to lower the previous figures for pressures in the renal vein and inferior vena cava by the actual distance between the two zero points, depending on the anteriorposterior chest diameter.

The pressure differences for these two groups are summarized in Table $I, b$ and Table II, b, and shown graphically in Figure 1. Disregarding the $20 \mathrm{~mm}$. difference between renal vein and vena cava in accordance with the above discussion, it is seen that in general the gradient of pressure differences flattens out in the group with congestive failure. This is to be anticipated because of the damming up of pressure behind the right heart.

\section{DISCUSSION}

It is well established that in chronic congestive heart failure there is a reduction in renal blood flow out of proportion to the decreased cardiac output, a lesser reduction of glomerular filtration rate and a retention of sodium (and water) by the kidneys $(1,3,7,8,11)$. It was believed by Seymour and his associates (6) and by Futcher and Schroeder (9) that the low renal blood flow of congestive failure is due to elevated venous pressure, Seymour's data suggesting that as compensation was restored following digitalis the venous pressure fell and the renal blood flow increased out of proportion to the change in filtration rate. This interpretation was questioned by Merrill (3), who emphasized that the decrease in renal blood flow was unrelated either to peripheral venous pressure (renal venous pressures were not measured) or to the pressure in the right auricle (and presumably in the renal vein), but was related to the cardiac output; the relatively high filtration rate, in his opinion, was caused by efferent arteriolar constriction. Mokotoff and his colleagues accepted this view (7), pointing out that the mean arterial pressure in cardiac patients is normal and that the reduced renal plasma flow is not due to a decrease in the driving pressure but to increased resistance to flow.

Blake, Wégria, Keating and Ward (13) have stated that a rise in renal venous pressure in one kidney of the dog causes an increased tubular reabsorption of sodium and water in that kidney, with no significant change in renal plasma flow or glomerular filtration rate. Since the effect is con- 
fined to the kidney in which the renal venous pressure was raised, they assume that the mechanism is mechanical and local and not related to release of pituitary, adrenal or hepatic hormones. Sodium retention begins rather abruptly at a different pressure level in each dog (as low as 160 $\mathrm{mm}$. saline), and increases in extent with further pressure increments and with the duration of increased pressure. Elevation of venous pressure to $550 \mathrm{~mm}$. saline and beyond decreased renal blood flow and filtration rate.

Selkurt, Hall, and Spencer (19), under similar experimental conditions, however, report that the renal blood flow and filtration rate decrease proportionally as the perfusion pressure across the renal circuit is decreased. An elevation of renal venous pressure from 7.5 to $22.4 \mathrm{~mm}$. $\mathrm{Hg}$ (decreasing the A-V pressure difference by about 11.5 per cent), reduced renal blood flow and filtration rate by 15 per cent with no change in filtration fraction. This is in agreement with the abdominal compression studies of Bradley and Bradley (14) on human subjects. The difference in results of Blake and associates remains to be explained.

Earle and his colleagues (20) have shown that following intravenous digoxin in patients with congestive heart failure there is a prompt increase in water and sodium excretion, even in the absence of significant change in filtration rate, renal plasma flow or filtration fraction. Water and electrolyte excretion appear to be inversely related to the venous pressure. These authors state "that increased renal venous pressure may play an important role in retention of water and sodium in congestive heart failure in man."

The problem of whether an increase in renal venous pressure in chronic congestive failure can per se account for the marked reduction in renal plasma flow and glomerular filtration rate characteristic of this condition can be examined by utilizing the equations of Gomez (21-23) to calculate the relative importance of the various components of resistance across the renal circuit. Using the accepted figures for control subjects (24), typical values from the literature $(3,7,8,11)$ for patients with congestive heart failure and the average values for renal venous pressure in these two groups (corrected to $\mathrm{mm}$. $\mathrm{Hg}$ ), we would arrive at the data given in Table III.

The overall renal resistance is clearly increased in congestive heart failure, the increase amounting in the average to 146 per cent. The average increase in afferent resistance is 200 per cent, in efferent resistance 110 per cent and in venous resistance 172 per cent. In relation to overall resistance, however, the venous component represents only about 18 per cent. In theory, assuming no alterations in the permeability coefficient of the glomerular membrane, an increased filtration fraction may be expected where efferent resistance is increased, irrespective of afferent resistance.

By substituting an elevated $(22 \mathrm{~mm}$. $\mathrm{Hg}$ ) for control $(11 \mathrm{~mm} . \mathrm{Hg})$ renal venous pressure in the above calculations on the control subject, the renal blood flow would be reduced from $1200 \mathrm{cc}$./ $\mathrm{min}$. to $1032 \mathrm{cc}$./min., representing a reduction of only 14 per cent. This calculation is in accord with the results obtained by Selkurt and associates (19)

TABLE III

Renal Vascular Resistance

\begin{tabular}{|c|c|c|c|c|c|c|c|c|c|c|c|}
\hline \multicolumn{8}{|c|}{ Typical data*' } & \multicolumn{4}{|c|}{ Calculated resistance*† } \\
\hline & Hct. & Pm & RBF & RPF & GFR & $\mathbf{h}_{\mathbf{o}}$ & RVP & $\mathbf{R w}$ & $\mathbf{R a}$ & $\mathbf{R e}$ & $\mathbf{R v}$ \\
\hline Control & $\begin{array}{c}\text { per cent } \\
40\end{array}$ & $\begin{array}{c}m m . H g \\
90\end{array}$ & $\begin{array}{c}c c . / \min . \\
1209\end{array}$ & $\begin{array}{c}c c . / \min . \\
697\end{array}$ & $\begin{array}{c}c c . / \min . \\
130\end{array}$ & $\begin{array}{c}m m . \mathrm{Hg} \\
25\end{array}$ & $\begin{array}{c}m m . H g \\
11\end{array}$ & 3.95 & 1.5 & 1.94 & .7 \\
\hline Cardiac & 45 & 90 & 420 & 232 & 80 & 25 & 22 & 9.71 & 4.5 & 4.11 & 1.9 \\
\hline $\begin{array}{c}\text { Per cent of } \\
\text { increase }\end{array}$ & & & & & & & & $146 \%$ & $200 \%$ & $110 \%$ & $172 \%$ \\
\hline
\end{tabular}

* Hct. = hematocrit; $\mathrm{Pm}=$ mean arterial pressure; $\mathrm{RBF}=$ renal blood flow; $\mathrm{RPF}=$ renal plasma flow; GFR $=$ glomerular filtration rate; $h_{0}=$ oncotic pressure; $R V P=$ renal vein pressure; $R w=$ overall renal reistance; $R a=$ renal afferent arteriolar resistance; $R e=$ renal efferent arteriolar resistance; $R v=$ post-peritubular capillary resistance. $\dagger$ Resistance calculated as $\mathrm{mm}$. $\mathrm{Hg} / \mathrm{cc}$. $/ \mathrm{sec}$. 
during increased renal venous pressure in the dog, and by Bradley and Bradley (14) during abdominal compression in man. We may conclude that in congestive heart failure, active constriction of the afferent and efferent arterioles largely accounts for the changes in clearances, the increased renal venous pressure being an additional factor in some cases only.

Whether the increased renal venous pressure per se adds another mechanism promoting sodium retention $(10,13,19,20)$ must remain a matter of speculation until more is known about the tubular mechanism of sodium reabsorption. The fact that there are important differences in the manner in which sodium and saline are handled by the $\operatorname{dog}(25)$ and man (26) requires that results obtained on the dog be applied to man with caution.

\section{SUMMARY}

1. A method is described for the determination of renal venous pressure in human subjects, with a discussion of the validity of the technique.

2. Pressures are recorded from the renal vein, inferior vena cava, right atrium and arm vein in a group of control subjects and in patients with right-sided heart failure. The renal venous pressure in the latter group is approximately twice that of the former.

3. Pressure differences between these four sites are compared in the two groups, and demonstrate elevated pressures with smaller differences between the atrium and all other sites in the subjects with congestive failure.

4. The role of elevated renal venous pressure in reducing the renal blood flow and filtration rate in congestive failure is discussed. Afferent, efferent and total renal resistance are substantially increased over the normal values in subjects in congestive heart failure, demonstrating constriction of both afferent and efferent arterioles. Renal vasomotor changes are responsible in great part for decreased renal plasma flow and filtration rate. In no instance is the rise in renal venous pressure of sufficient magnitude to cause the observed degree of renal ischemia.

\section{ACKNOWLEDGMENTS}

The authors are indebted to Miss Pauline Cohan and to Miss Alfonia Urban, R.N., for their assistance in this investigation.

\section{BIBLIOGRAPHY}

1. Leiter, L., The role of sodium chloride in the mechanism and treatment of congestive heart failure. Bull. N. Y. Acad. Med., 1948, 24, 702.

2. Warren, J. V., and Stead, E. A., Jr., Fluid dynamics in chronic congestive heart failure: an interpretation of the mechanisms producing the edema, increased plasma volume and elevated venous pressure in certain patients with prolonged congestive failure. Arch. Int. Med., 1944, 73, 138.

3. Merrill, A. J., Edema and decreased renal blood flow in patients with chronic congestive heart failure: evidence of "forward failure" as the primary cause of edema. J. Clin. Invest., 1946, 25, 389.

4. Merrill, A. J., and Cargill, W. H., "Forward failure": the mechanism of cardiac edema formation in subjects with normal or high cardiac outputs. J. Clin. Invest., 1947, 26, 1190.

5. Merrill, A. J., Edema in heart failure. Bull. N. Y. Acad. Med., 1948, 24, 607.

6. Seymour, W. B., Pritchard, W. H., Longley, L. P., and Hayman, J. M., Jr., Cardiac output, blood and interstitial fluid volumes, total circulating serum protein and kidney function during cardiac failure and after improvement. J. Clin. Invest., 1942, 21, 229.

7. Mokotoff, R., Ross, G., and Leiter, L., Renal plasma flow and sodium reabsorption and excretion in congestive heart failure. J. Clin. Invest., 1948, 27, 1.

8. Brigges, A. P., Fowell, D. M., Hamilton, W. F., Remington, J. W., Wheeler, N. C., and Winslow, J. A., Renal and circulatory factors in the edema formation of congestive heart failure. J. Clin. Invest., 1948, 27, 810.

9. Futcher, P. H., and Schroeder, H. A., Studies on congestive heart failure. II. Impaired renal excretion of sodium chloride. Am. J. M. Sc., 1942, 204, 52.

10. Bradley, S. E., and Blake, W. D., Pathogenesis of renal dysfunction during congestive heart failure. Am. J. Med., 1949, 6, 470.

11. Breed, E. S., Baldwin, D., and Maxwell, M. H., unpublished data.

12. Reichsman, F., and Grant, H., Some observations on pathogenesis of edema in cardiac failure. Am. Heart J., 1946, 32, 438.

13. Blake, W. D., Wégria, R., Keating, R. P., and Ward, $H$. P., The effect of increased renal venous pressure on renal function. Am. J. Physiol., 1949, 157, 1.

14. Bradley, S. E., and Bradley, G. P., The effect of increased intra-abdominal pressure on renal function in man. J. Clin. Invest., 1947, 26, 1010.

15. Warren, J. V., Brannon, E. S., and Merrill, A. J., Method of obtaining renal venous blood in unanesthetized persons with observations on the extraction of oxygen and sodium para-amino hippurate. Science, 1944, 100, 108. 
16. Cournand, A., Riley, R. L., Bradley, S. E., Breed, E. S., Noble, R. P., Lauson, H. D., Gregerson, M. I., and Richards, D. W., Studies of the circulation in clinical shock. Surgery, 1943, 13, 964.

17. Richards, D. W., Jr., Cournand, A., Darling, R. C., Gillespie, W. H., and Baldwin, E. DeF., Pressure of blood in the right auricle in animals and in man: under normal conditions and in right heart failure. Am. J. Physiol., 1942, 136, 115.

18. Bradley, S. E., Personal communication.

19. Selkurt, E. W., Hall, P. E., and Spencer, M. P., Response of renal blood flow and clearance to graded partial obstruction of the renal vein. Am. J. Physiol., 1949, 157, 40.

20. Earle, D. P., Jr., Farber, S. J., Alexander, J. D., and Eichna, L. W., Effect of treatment on renal func- tions and electrolyte excretion in congestive heart failure. J. Clin. Invest., 1949, 28, 778.

21. Gomez, D. M., Hemodynamics of the renal circulation. La Revue Scientifique, 1947, Ext. 3272, 451.

22. Gomez, D. M., Calculation of effective afferent and efferent renal resistance. Federation Proc., 1948, $7,41$.

23. Smith, H. W., The Kidney Structure and Function in Health and Disease. Oxford University Press, New York. (In press).

24. Smith, H. W., Lectures on the Kidney. University Extension Division, University of Kansas, Lawrence, Kansas, 1943.

25. Ladd, M., and Raisz, L. G., The response of the normal dog to dietary sodium chloride. Am. J. Physiol., in press.

26. Crawford, B., and Ludemann, H., unpublished data. 